\title{
Ideology, Scientific Theory, and Social Work Practice*
}

\author{
by Susan P. Robbins, Pranab Chatterjee, \& Edward R. Canda
}

\begin{abstract}
This article discusses the philosophical and ideological nature of theory and examines the ways ideology becomes infused into social work theory and practice. The use of critical thought and specific evaluation criteria based on consistency with social work values are proposed.
\end{abstract}

IN RECENT TIMES, SOCIAL WORK and many of the helping professions have placed a heavy emphasis on practice that is based on scientifically derived theories and knowledge. The National Association of Social Workers (NASW) Code of Ethics explicitly mandates that professional practice include empirically based knowledge, the evaluation of programs and interventions, and that social workers "critically examine and keep current with emerging knowledge relevant to social work and fully use evaluation and research evidence in their professional practice" (NASW, 1996, p. 4) Thus, in our attempt to shape and mold professional practice, theories of causation, prevention, and intervention are expected to be empirically tested and verified, or, at the very least, lend themselves to empirical verification.

With this in mind, it seems important to ask "What is the actual basis of our current professional knowledge?" This is not an insignificant question because, unlike other helping professions, social workers are expected to be experts on not only the biological, psychological, social, cultural, economic, and political aspects of human behavior, but experts on assessment, prevention, and intervention at all levels of social systems as well. It is this very complexity, however, and the mandate that social workers examine both the person and the environment, that contributes to the unique mission of social work practice. However, according to Kilty and Meenaghan (1995), the recent focus on empirical verification has, in part, contributed to an incomplete focus on better indi- vidual and family outcomes rather than an understanding of the larger issues and societal structures that contribute to risk and maintain social and economic inequality. Citing Abramovitz's (1983) concern about the narrowness of our conceptual frameworks, they propose that the selected use of scientifically based methods has unwittingly obscured the full range of value choices and research that the profession might pursue in its study of people and environments.

There have been numerous debates in the professional literature about the nature of requisite knowledge for the profession (see, for example, Atherton, 1993; Fischer, 1981; Franklin, 1995; Fraser et al.; 1991; Gibson \& Nurius, 1992; Goldstein, 1992; Harrison, Hudson \& Thyer, 1992; Hartman, 1990; 1992; Heineman, 1981; Herr, 1995; Hudson, 1982; Imre, 1984; Kirk, 1996; Klein \& Bloom, 1995; Kondrat, 1995; Lindsey \& Kirk, 1992; Minahan \& Pincus, 1977; Reid, 1994; Rein \& White, 1981; Rodwell, 1987; Sheldon, 1978; Staller \& Kirk, 1998; Tucker, 1996; Weick, 1987; Witkin, 1991; 1992). To date, apart from the general mandates of curricular policies set by the Council on Social Work Education, there is little consensus about essential knowledge for professional practice. In addition to the traditional split between micro and macro practice knowledge and skills, the debate tends to be heavily polarized into two competing camps - those who argue for the primacy of scientific and empirically based knowledge vs. those who believe in the art of social work gained from practice wis-

"Parts of this article are adapted from Robbins, S. P., Chatterjee, P., Ær Canda, E. R. (1998). Contemporary Human Behavior Theory: A Critical Perspective for Social Work. Boston: Allyn \& Bacon. 
dom, the value of the helping relationship, and subjective insights gained from client self-reports and case studies. A more recent development in this debate is the polemic schism between scientific knowledge and constructionist/constructivist knowledge.

At the extremes of these positions, there is little, if any, room for common ground. A more moderate position accepts and advocates for a combination of both. Although reasonable and, in fact, somewhat seductive at face value, this middle stance generally ignores the ideological biases inherent in both extremes and often fails to address the consequences of undisciplined eclecticism in which all perspectives are equally valued and uncritically embraced. We are not suggesting that one must choose between camps but, rather, that such choices must be made mindfully and with a full appreciation of the philosophical and ideological differences that underlie these disparate positions about the nature of knowledge and the essential knowledge for practice.

Social work is, by its very nature, a value-based profession. Although values and knowledge are seen as being separate but interactive components of professional decisions and action (see Bartlett, 1970; Rosenthal, 1992), there is a tendency to overlook the fact that values and ideological positions are inherent in all theory and knowledge. When theory and knowledge are presented as "objective" truths that can be empirically demonstrated and objectively verified through supposedly impartial scientific methods, it becomes all too easy to bypass the philosophical and ideological underpinnings of what we know. As Kilty and Meenaghan (1995) have pointed out, the convergence of professionalism and scientific inquiry in social work has led us to lose sight of critical questions about the use of scientific methodologies, the political contexts in which they occur, the goals that we seek, and the related practical implications for social work practice. Despite the classic and contemporary debates in the social science literature, we contend that neither theory, knowledge, nor scientific inquiry are totally value free, and the conceptual differentiation between knowledge and values easily can lead to a misconception about the nature of theoretical knowledge, which we discuss below.

In the field of social work, and in the social sciences in general, much of our knowledge about human behavior and human existence is speculative in nature. All too often, theories are misrepresented as "facts" and are seen as universal mandates for normative and expected behavior, be it at the individual, group, organizational, community, or societal level. As a beginning step in understanding our knowledge base, we believe it is important to critically examine the nature of theories in order to evaluate both the strengths and the inherent limitations of our knowledge about people and their environments.

\section{The Nature of Theories}

Theories are an important part of our knowledge base because they assist in our attempts to understand various aspects of human behavior as well as our interactions with our clients. Theories, however, not only provide us with a framework to help us organize our observations for understanding, but are also used scientifically for the purposes of explanation and prediction (Dubin, 1969). Theories do not simply emerge on their own (although some are derived from a flash of insight), but are constructed through systematic cognitive and experiential processes of inductive and deductive reasoning and through the interplay of empirical and theoretical structures. Empirical structures are those that are experienced with our senses, in our environment, while theoretical structures are those that we "construct in our mind's eye to model the empirical system" [emphasis added] (Dubin, 1969, p. 9). Thus, theories are based on cognitive abstractions that develop over time and are both a description and generalization from our experiences.

Through the repeated processes of observation and abstraction, theories are formulated in such a way that they ideally lead to the eventual generation of hypotheses and scientific studies that will confirm (or falsify) these abstractions. The scientific confirmation of a theory is a necessary step if the theory is to become accepted as factual knowledge. This is especially important because theories not only prescribe ideals for human functioning but also offer guidelines for practice.

\section{The Social Construction of Theories}

Theories not only arise from the cognitive and experiential processes of individuals described above, but from social processes as well. As we have noted elsewhere (Robbins, Chatterjee, \& Canda, 1998), all knowledge - including theoretical knowledge - is developed within a specific social, cultural, and historical context. These contexts, in turn, have a profound influence on the content of theory.

In The Social Construction of Reality, Berger and Luckmann (1966) proposed that all knowledge is socially constructed, including our knowledge of what is "real." Because people are born into a society and culture with existing norms and predefined patterns of conduct, 
definitions of what is "real," are socially transmitted from one generation to the next and are further reinforced by social sanctions. These existing group definitions are learned and internalized through the process of socialization, and this knowledge becomes part of one's worldview and ideology. People rarely, if ever, stop to question their worldview and, unless challenged, they take it more or less for granted that the way in which they see the world is the same for everyone (Berger $\&$ Luckmann, 1966; Robbins et al., 1998).

Not surprisingly, theorists often operate under these very same assumptions. As a consequence, they bring the biases of their own gender, class, culture, and sexual orientation, for example, into their work. Theories, therefore, are often extensions of the theorists themselves because their concerns, values, and overall worldview are often reflected in the theories that they construct. This is not unusual, but it becomes problematic when a theory is applied universally and thought to be representative of the broader human experience, in general. It is even more problematic when it sets standards or ideals for development and behavior that are not, in fact, universal.

\section{Ideology, Scientific Theory, and Social Work Practice}

Due to the fact that social work emphasizes practice that is based on scientific theories of human behavior, causation, prevention, and intervention, we might incorrectly believe that ideology has no place in theory construction or in our professional knowledge base. Despite the veil of scientific objectivity, theories are not free from the influence of ideology. They are inherently ideological in nature because they cannot be "free of material interests and uncompromised by moral and cultural commitments" (Brown \& Martin, 1991, p. 11). As Kilty and Meenaghan (1995, p. 452) note, science, itself, is always political and value laden and scientific methodology is "always contaminated by the political and economic context." In a similar vein, Campbell (1981, p. 22) has proposed that:

... theories are ideological in that even the most neutral-looking factual claims about social phenomena can be taken up and used in the competition between social groups for positions of power, wealth, and influence...

It should not be surprising, then, to find that the under- lying assumptions of any given theory can be associated with different political positions and are often used to support or oppose specific interventions and policies that affect our clients.

In addition, it is important to recognize that theories can become self-fulfilling or self-refuting based on our own attitudes and beliefs. For example, the beliefs that we hold about ourselves, our clients, our relationships, our families, our society, and our economic and political systems can influence our actions which, in turn, may serve to validate (or refute) a certain theoretical perspective (Campbell, 1981). As we have noted elsewhere (Robbins et al., 1998), a person who strongly believes, for example, that early childhood experiences are at the root of problems in adulthood will tend to look for previously undiscovered traumatic experiences in the family of origin. This will likely intensify, create, or bring to the surface unpleasant memories that might have been less pronounced if the source of the problem was attributed to present day stressors. Similarly, a belief in and adherence to theories that promote individuation as a normative developmental goal will lead people to seek independence rather than interdependence; in doing so, this will validate one developmental path while refuting the other.

According to Campbell (1981, p. 22), theories are "in the complicated position of being a part of the reality they purport to analyze." This embedded relationship, coupled with the way in which theories are used to advocate for specific interventions and policies, make it especially important for us to understand both the practical and political implications of a given theory. In order to gain this understanding, we must be particularly aware of the ideological underpinnings inherent in our theories and knowledge so that they can be subjected to thoughtful and critical analysis. The literature is replete with debates about value-free social science; it is our firm position that value-free social science and, by extension, a value-free knowledge base, is simply not possible.

Ideology is present not only in our theoretical knowledge base but in all professional social work settings as well. Flowchart 1 demonstrates the way in which ideology directly influences the helping situation and indirectly influences both scientific theory and the related intervention strategies that are used in practice.

There are at least two ways to define a helping situation, as illustrated in Flowchart 1: (1) a professional definition, which emerges from the application of scientific theory, but under the influence of existing ideologies that are often unknown; and (2) a popular definition, which develops from existing ideologies (or normative knowl- 
edge) of society and, most typically, a rather inadequate knowledge of scientific theory. Due to the fact that there are many types of ideologies and scientific theories, this leads to numerous professional definitions of the helping situation (variations of the pathway to the left) as well as many popular definitions (variations of the pathway to the right). However, as indicated by the arrows between the two, these are not totally independent, and may, at times, influence each other directly or indirectly (Robbins et al. 1998).
Ideological Factors in the Historical and Professional Context of Practice and Our Choice of Theories

As seen in Flowchart 1, the definitions and norms that govern professional practice already exist when a client seeks (or is required to seek) assistance and are based on a preexisting definition of the situation (see Chatterjee, 1985, 1990; Chatterjee \& Bailey, 1993; Chatterjee \&

Flowchart 1. The Interplay Between Scientific Theory and Ideology.

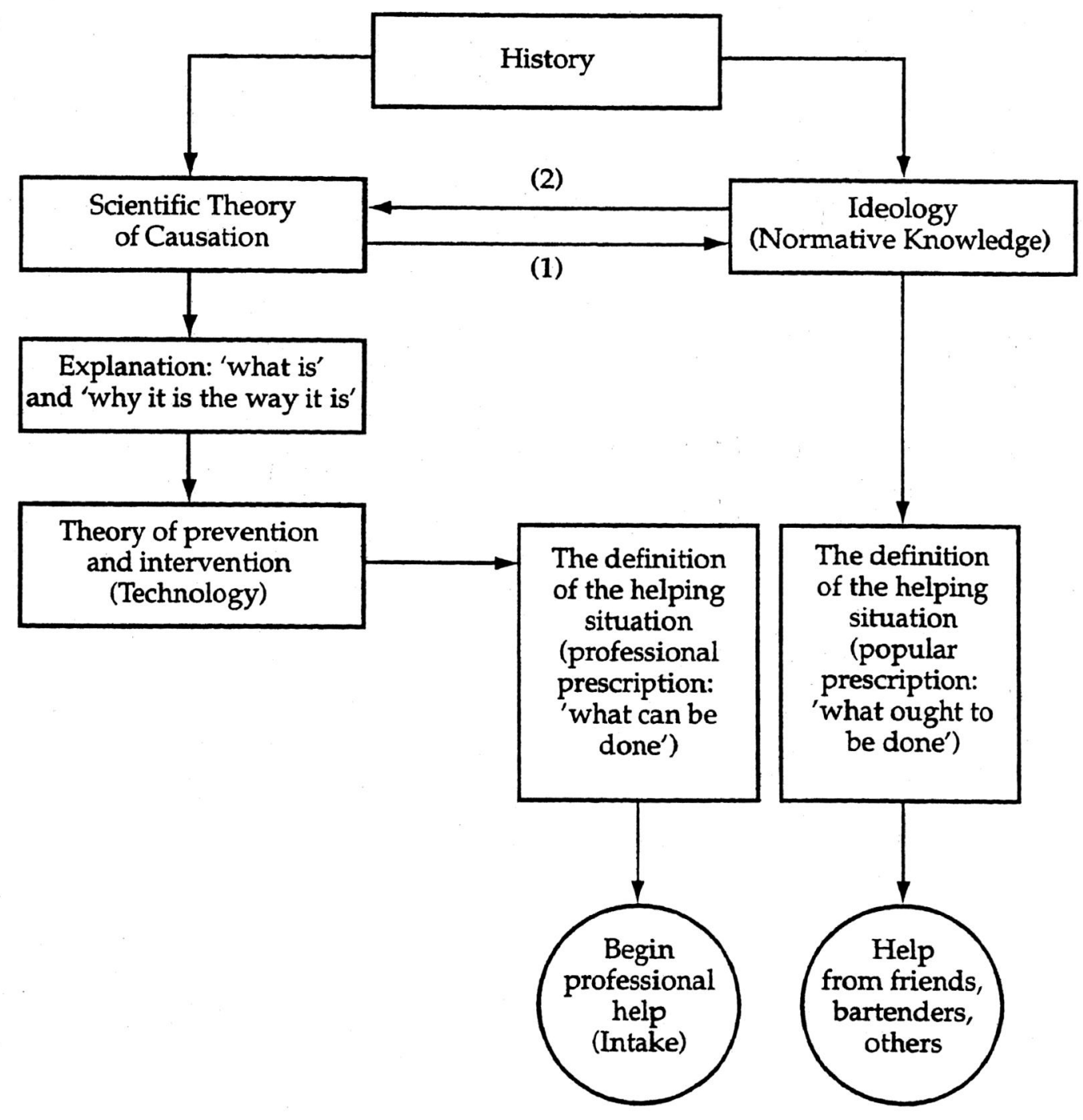

(C) 1998, S.P. Robbins, P. Chatterjee, \& E.R. Canda 
Hilbert, 1986). Ideology is embedded in the helping situation itself as well as in its historical and organizational contexts; it defines and sustains not only the context of helping, but also the interactions between the persons involved. For example, it defines the role and "appropriate" behavior of the client, the role and "appropriate" professional behavior of the social worker, their respective statuses, and whether, how, and how much the social worker should be paid.

Theories, therefore, are often

\section{extensions of the theorists themselves}

\section{because their concerns, values, \\ and overall worldview are often reflected} in the theories that they construct.

Historically, in the quest for professional status, social work's relatively early adoption of psychoanalytic and psychodynamic theory led to a narrow individual and intrapsychic view of people and ushered in a medical model of practice that represented a sharp departure from the socioeconomic base of practice that was apparent in the earlier Settlement House Movement (Trattner, 1986, p. 245). Although our professional theory base has now been expanded to include systems theory and an ecological perspective, psychological perspectives on the life span continue to dominate much of our social work knowledge about human behavior. Despite the systemic and ecological focus on client problems and their potential for growth rather than on illness and pathology, the current use of systems-based theories has largely retained a micro and meso level focus for direct practice rather than a broader focus for social action (Robbins et al., 1998). In both our early and ongoing efforts to achieve increased professionalization we have selected some theories and omitted others - some by accident and others by design. Given our historical struggle for social approval, professional status, and our recent emphasis on empirical verification, it is not surprising that the theories that we have adopted and defined as central to our knowledge base tend to be both psychologically based and politically conservative (Abramovitz, 1983; Kilty \& Meenaghan, 1995; Robbins et al., 1998).

\section{Where Do We Go From Here? Expanding Our Theory Base for Contemporary and Future Practice}

As we move forward into the next millennium, we are faced with critical value choices about essential knowledge for practice. If practice is to adequately reflect our mission for social justice and our holistic concern for both the person and the environment, we believe that our knowledge must be expanded to include a broad multidisciplinary theory base that will provide a more comprehensive view of the human condition and the lives of our clients. Due to the complexity of human behavior and human experience, it is critical that our theory base encompass a broad range of theories and knowledge from the human and social sciences. We concur with Kilty and Meenaghan (1995, p. 452) that it is important to recognize the political and value laden nature of science, while at the same time:

... identifying values and value options; defin-
ing problems and conditions, especially the no-
tions of chance and risk, as they relate to differ-
ent groups in society; selecting goals that focus
on groups and risks as well as goals that focus
on individuals and need; and designing and eval-
uating interventions that are preventive as well
as restorative to groups, recognizing that such
interventions are tied to bigger issues and struc-
tures in society.

In defining and choosing a theory base that will provide this type of holistic perspective, we believe that it is important for us to now look both outward and inward.

First, in looking outward, we believe that it is particularly relevant for social work to draw on the assumptions of critical theory to analyze the social, ideological, and economic structures of society and their impact on individual problems. Critical theory posits that, "Most individual problems are in fact social problems, caused by an inequitable social structure" (Findlay, 1978, p. 55). Due to the politically conservative theory base that has predominated social work, the addition of this perspective is long overdue. In order to demystify ideologically based issues of power and truth, Witkin and Gottschalk (1988, p. 218) have noted that theory for practice must include "a reflexive element concerning its historical, cultural, and political/economic significance." This is particularly important because these macro level concerns 
have significant impact on our clients' lives and the way in which we view our clients. Fisher and Karger (1997) have argued that macro contextualization be put at the base of social work practice. With the exception of feminist and constructionist thought, these concerns have been seriously minimized or ignored in our predominantly psychological and systemic theories.

Next, in looking inward, social workers must become better educated in two distinct areas that have been largely neglected in our theory base; 1) biology and genetics; and 2) Western and non-Western concepts of spirituality. It is critical that our knowledge include the most contemporary and well-replicated research about the relative influence of genetics, biological, and neurobiological factors in behavior. Although there is now a tendency in the fields of psychiatry and medicine to be reductionistic and overemphasize the role of neurobiology in the creation of psychological disorders (see Valenstein, 1998), we cannot ignore the fact that human behavior expresses the complex interactions of biology and environment.

Further, due to the numerous, diverse, and conflicting religious and non-religion spiritual perspectives that shape our lives and the lives of our clients, our social work settings, and social institutions, it is imperative that we also gain a better and broader understanding of spirituality and religion. Because spirituality and religion are pervasive in many of our clients' lives as well as in many of our social work settings, it is essential that we gain substantial knowledge in this area and become familiar with both theories and philosophical thought that address these issues (see Canda, 1988; 1989; 1991; 1996; 1997). Very significantly, spirituality can also motivate action toward social justice, a guiding value in social work practice.

Finally, as we expand our theory base and define essential knowledge for practice, we believe that it is important to add an element that is often absent in most social work literature - an analysis of theory that is based on critical thinking. As we have noted elsewhere (Robbins et al., 1998), the inherently ideological nature of theories makes it particularly important for us to examine theories systematically through the use of rigorous intellectual analysis, criticism, and evaluation. Most commonly, theories are analyzed simplistically and uncritically in relation to their strengths and weaknesses, which are often presented as having equal merit. We strongly believe that critical thinking is a necessary component of social work, and one which, according Gibbs and Gambrill (1996), is often missing in professional practice. Critical thought goes beyond a simple appraisal of the claims and arguments that are embodied in a theory and involves the use of specific standards in evaluating evidence combined with a fair and thorough critique of alternative views. Very importantly, critical analysis should also aid us in recognizing the longstanding problems of determinism and reductionism that are inherent in all theories.

\section{The Challenge of Critical Analysis of Theory: Comparing Apples and Oranges}

Given the broad theoretical base that is necessary to understand the complexity of our clients' lives and circumstances, one of the important challenges that we face is delineating specific criteria for critical analysis of theory that will allow us to compare and evaluate, for example, theories from the biological, psychological, anthropological, social, economic, and political sciences. At its best, a given theory may describe some of the distinct threads of the fabric of our clients' lives and experiences, but will never fully capture a holistic view of the person or the fabric itself. Thus, some theories address biological and psychological factors, but ignore the political and economic context. Likewise, other theories focus solely on political, historical, and economic factors and exclude psychological ones. Some theories may even include multiple factors but emphasize one over the others. Comparing and evaluating such disparate theories may appear similar to comparing apples and oranges because the obvious differences can easily obscure the fact that they can, in fact, be compared systematically. However, before delineating the criteria that we believe should be used in the evaluation of theory, we first describe three approaches that should be avoided.

\section{Approaches to Avoid in Choosing a Theory Base}

In order to forge the necessary linkages between theory and practice, it is crucial to examine different approaches that are sometimes used in selecting and applying theories for practice. We caution against three approaches that we have seen promoted in social work: rejecting theory; theoretical dogmatism; and undisciplined eclecticism (Robbins et al., 1998).

Some may believe that theory is useless or irrelevant and they summarily reject the use of theory and focus, instead, on specific practice methods and interventions in 
their work with clients. We believe that this is unsound because social work practice, practice methods, and interventions are informed by values, ideology, and assumptions about human nature that are often theoretically based. When this is ignored, it increases the risk of imposing an unwitting or hidden agenda on clients.

A second approach to avoid is theoretical dogmatism. This occurs when practitioners believe a particular theory to be universally true, and they apply their theory of choice to all clients and client situations. Such theoretical loyalty excludes the use of other theories that might be more relevant to an individual client's needs and circumstances. Thus, we have loyal neo-Freudians, behaviorists, Jungians, feminists, constructionists, ego psychologists, systems theorists, conflict theorists, etc. Dogmatism of this sort obscures the limitations and constraints that are inherent in theories due to their social construction, and we lose sight of the fact that theories are simplifications of reality. Theoretical dogmatism reduces all clients and situations into whatever terms are comfortable to the practitioner. This is particularly dangerous because it submerges the reality of the client in the theoretical assumptions of the practitioner.

\section{Theories assist in our attempts to understand}

\section{various aspects of human behavior}

\section{as well as our interactions with our clients.}

A third approach we caution against is undisciplined eclecticism. Although social workers may recognize the importance of theory, they may not have achieved an adequate grasp of any particular theory. As a result, they may mix and match bits and pieces from different theories and practice approaches that they have learned. However, combining theories in this way is every bit as controlling as dogmatism; it is simply less disciplined and poorly informed.

The approach that we propose and delineate below is based on critical analysis and reflection and is substantially different from ignoring theory, dogmatically adhering to a theory, or choosing a theory in an undisciplined fashion. A critically reflective approach involves cultivating clear awareness about one's own values, goals, practice commitments, strengths, and limitations. It also involves developing a thorough knowledge of a wide range of theories that deal with the person and the environment in a holistic manner. It requires making an informed and reflective evaluation about each theory as well as an examination of the theory's fit with social work values. Finally, it requires careful professional judgment about the relevance of a given theory to a particular situation in collaboration with the client.

\section{Criteria for Critically Evaluating Theory and Knowledge for Practice}

As noted above, critical thought involves a rigorous analysis of theory that includes use of specific standards and criteria, the evaluation of existing evidence, and fair consideration and critique of alternative views. With this in mind, we propose three specific criteria for theory evaluation that we believe to be most relevant for social work practice.

Criterion 1: Theories for social work practice should be consistent with social work values and ethics. Due to the fact that social work practice is governed by a professional Code of Ethics that is unique to social work, one essential criterion for theory selection is that the theories that we use in practice should both reflect and be consistent with the basic tenets of our social work values. Social work has embodied a set of values and ethics that are expressed not only in our Code of Ethics, but in the design of our professional curriculum as well. These values include, but are not limited to, respect for the inherent dignity and worth of the person; helping people achieve optimal health and well-being; the importance of client self-determination; promoting respect for human diversity; challenging social injustice; and working toward the goal of empowerment for individuals and groups. We discuss this at great length and place our primary focus on this criterion because it is most central to our professional identification as social workers and to the unique mission of the profession.

While psychological life span theory has placed emphasis on psychological and physical well-being and systemic/ecological theory has made us more aware of the issue of "goodness-of fit" between people and their environments, our primary theories remain focused on extremely narrow social and physical dimensions of environment. In order to more fully address the insidious forms of social injustice that are created and supported by oppression and discrimination, it is particularly important for us to expand this focus to explicitly include the notion of economic well-being as well as an understanding of the role of our political system in initiating 
and maintaining oppression and injustice. Additionally, as noted above, a truly holistic view of people must also address issues of biology, genetics, and spirituality as well, areas that have recently gained increasing acceptance, but have not yet been systematically incorporated into our theory base.

Although client self-determination has long been a central value in social work (see Ewalt \& Mokuau, 1995; Freedberg, 1989; Haynes \& Holmes, 1994; Rothman, Smith, Nakashima, Paterson \& Mustin, 1996; Perlman, 1965; Biestek, 1978; Weick \& Pope, 1988), this has not always been reflected in our theory base. It is critical that we move away from an over-reliance on theories that are inherently reductionistic, deterministic, and pathologybased. When clients are seen primarily as causal products of faulty biology, neurotransmission, early childhood influences, or their socio-cultural environments, for example, we rob them of self-determination and free will and ultimately ignore or minimize our clients' potential to grow and change.

Further, respect for the inherent dignity and worth of people and respect for human diversity are central to our value base and an important area for theory analysis. Most theories claim to be universal, despite the fact that few can live up to this claim. Because most theorists write from their personal and cultural frame of reference, attempts to generalize are often problematic, to say the least. Given that the vast majority of our theories have been classically authored by white, middle- to upper-class, Western European and American men (many of whom are now dead), it is not surprising to find biases of race, gender, culture, religion, sexual orientation, and social class inherent in much of our theory base. Although there have been corrective tendencies in recent years (many of which contain their own - albeit different - biases), social work theory continues to be dominated by these biased conceptions of human behavior and human experience (Robbins, et al., 1998).

At issue here is not who authors a given theory, but rather, to whom the theory is applied - and the consequences of that application. People are most often portrayed as deficient when they do not fit a theory's constructs (Gilligan, 1982; Howard and Scott, 1981; Robbins, 1984). Because it is rare that we question the validity of a well-accepted theory, we come to question the validity and worth of the person instead. This is antithetical to the values of respecting the inherent value and worth of the person and respecting diversity. The ideological nature of theory often creates serious constraints on our ability to appreciate differences that do not conform to our mainstream social norms (Robbins et al., 1998).

Social work has a specific commitment to challenge social injustice and to understand and promote empowerment and strength at both personal and political levels (Gutierrez \& Ortega, 1991; Hartman, 1993; Lee, 1994; Saleebey, 1992; Simon, 1994; Weick \& Saleebey, 1995). As a proactive response to personal and societal forces that oppress and restrict human potential and well-being, empowerment practice is aimed at assisting people who experience systematic forms of discrimination, harassment, and oppression. It becomes imperative, then, to examine the implications of theories for political consciousness raising, enhancing self-efficacy, and supporting collective action.

A focus on empowerment is strongly supported by the strengths perspective, a practical and philosophical stance that emphasizes the human capacity for resiliency, courage, strength in the face of adversity, ingenuity in accessing and creating resources, and the right of individuals to form their own aspirations and definitions of their situations (Rapp \& Wintersteen, 1989; Saleebey, 1992, 1996; Weick, Rapp, Sullivan, \& Kisthardt, 1989). Our cardinal values of respecting people's inherent dignity and worth and the importance of client self-determination are clearly embodied in this approach. Although the strengths perspective has been accused of "reframing misery," ignoring reality, and taking a Pollyannaish approach that ignores dangerous and destructive client behaviors, Saleebey (1996) has countered these criticisms by directly addressing the misconceptions inherent in these arguments.

Perhaps most importantly, the strengths perspective rejects models of pathology that have been widely used in social work and in the social sciences to describe oppressed groups. Theories that pathologize oppressed populations place a primary focus on deficit, illness, and problems and portray our clients as inherently deficient and problematic. In contrast, theories that are consistent with the strengths perspective portray people as being most likely to grow and develop when their strengths, rather than their problems, are recognized and supported. Perhaps most central to our professional values, the strengths perspective offers a basis from which helpers "become agents" of the focus group or individual and from which the group or individual is treated with dignity and respect and is regarded as having special "expertise" (Weick and Saleebey, 1995, p. 148). Importantly, the empowerment and strengths perspectives not only caution us to beware of theories that pathologize or blame the victim, but also challenge us to cull the insights from theories that are conducive to self-actualization and 
social justice (Robbins et al., 1998).

Thus, in evaluating a theory's consistency with social work values, it is important that we pay specific attention to the way in which a theory addresses - or fails to address - issues related to client dignity and worth, self-determination, helping clients achieve optimal health and well-being, respecting diversity, strengths and resiliency, challenging social injustice, and working toward empowerment. We propose that theories that address and embrace these concepts have more utility for social work practice than those that do not.

Criterion 2: Theories for social work practice should be subjected to scientific scrutiny, methodologically sound research, and be verifiable. Despite the fact the numerous methodological assumptions and issues underlie every theory, it is extremely important to know the degree to which a given theory has received empirical validation. Theories, by their very nature, are part of a scientific venture and thus, are more than mere opinions, ideology and politics notwithstanding. According to Cohen $(1989$, p. 22), the evaluation of theories "requires evidence, and the evaluation of evidence demands an evaluation of the methods by which the evidence was obtained." A critical analysis of theory, then, must also include both an empirical evaluation of the central concepts as well as an evaluation of the adequacy of the methods used.

We are not, however, promoting a narrow definition of research. Empirical evidence can be derived from direct experience gained through rigorous and replicated systematic inquiry that includes qualitative, quantitative, historical, and phenomenological research. It is important to recognize that theories are not only evaluated by research, but also offer implicit suggestions for the specific types of research that are most useful for the phenomena under consideration.

Thus, a determination of whether a theory's central concepts and main hypotheses are scientifically well grounded makes it necessary to also evaluate the adequacy of the proposed methods. In addition, we must evaluate the degree to which the theory is actually supported by evidence. If science is to inform practice, as called for by our Code of Ethics, it is critical to be able to distinguish between what a theorist has claimed in contrast to what has actually been empirically demonstrated (Robbins, 1995a; Robbins et al., 1998).

Criterion 3: Theories for social work practice should do no harm. Although this criterion has not been explicitly addressed in the social work literature, it is easily derived from the Code of Ethics and basic philosophical po- sitions that undergird the profession. (Check \& Asquith,1985; NASW, 1986). The Code of Ethics mandates that social workers act with integrity, behave in a trustworthy manner, be competent in their areas of practice, and continually increase their own professional knowledge and skills (NASW, 1996). These ethical mandates, combined with the requirement that practice be based on empirically validated knowledge, place a special obligation on social workers to not harm the people that they serve.

At face value, this might appear to be a superfluous criterion, given the high value placed on integrity, trustworthiness, and competence. However, given the ideological biases inherent in all theory and the serious problems that can result from theoretical dogmatism and undisciplined eclecticism, we believe that the mandate to "do no harm" is a necessary additional criterion for both professional practice and the evaluation of theory for practice. A practitioner's dogmatic adherence to unproven theories and dubious practice techniques, which are often based on personal or political ideology, can indeed cause serious and sometimes irreparable harm to clients (see Parr, 1996; Pendergrast, 1996; Robbins, 1995a, 1995b; 1997; Stocks, 1998). Unfortunately, existing ethical principles for practice do not address this issue with sufficient clarity.

The mandate to "do no harm" has long been a guiding principle in medicine, embodied in the Hippocratic Oath (Von Staden, 1996); we propose that it become an explicit obligation for professional social work practice and a criterion for theory evaluation as well.

\section{Conclusion}

As we begin to critically analyze the theories for practice, it is important to be aware of the ideological biases that result from the social construction of theory. We must also develop a profound understanding of the way in which theories can come to define "reality" and the impact this has on those who may not share in this reality. It is equally important for us to realize that the biases that may be the most difficult for us to detect are those related to our taken-for-granted cultural norms. It is our firm position that we must become aware of these biases if we are to serve our clients in ways that can lead to empowerment.

To repeat, our professional knowledge and theories have been based in recent times on a rather narrow conception of person and environment. Our choice of theories, disciplinary loyalties, as well as increased specialization, have led to a fragmented and incomplete view of the 
human condition, human behavior, and human experience. This has been further exacerbated in social work by our professional "split" into separate areas of clinical and community practice, each with its own theory base. We believe, however, that contemporary developments in society and in theory construction are now forcing us to see connections that were readily apparent to social work pioneers such as Jane Addams, Lillian Wald, Bertha Reynolds, and the many others involved in the early development of social work. As we step into the twentyfirst century, social work is in a unique position to renew its historical commitment to a holistic view of both people and their environments (Robbins et al. 1998).

We face numerous challenges, however, in our attempt to achieve such a holistic view. First, we must recognize the impact and importance of rapid technological and social change on our social institutions, organizational structures, family forms, and individual values, beliefs, and behaviors. Because all theory is developed within a specific historical context, we must also begin to critically examine the relevancy of any theory that does not adequately account for life in contemporary society. Further, we must be able and willing to openly question some of our deeply held assumptions about the nature of self, family, community, and society. And finally, we must be open to adopting new theories that more accurately reflect the changing economic, cultural, and psychological landscape of contemporary life as well as those that are consistent with our professional value base.

\section{References}

Abramovitz, M. (1983). Everyone is on welfare: The role of redistribution in social policy revisited. Social Work, 28, 440-444.

Atherton, C. R. (1993). Empiricists vs. social constructionists: Time for a cease fire. Families in Society, 74(10), 617-624.

Bartlett, H. M. (1970). The common base of social work practice. New York: National Association of Social Workers.

Berger, P. L., \& Luckmann, T. (1966). The social construction of reality. Garden City, New York: Anchor Books.

Brown, L. (1995). Lesbian identities: Concepts and issues. In A. D'Augelli \& C. Patterson (Eds.), Lesbian, gay and bisexual identities over the lifespan. New York: Oxford University Press.

Biestek, F. (1978). Client self-determination in social work. Chicago: Loyola University Press.

Campbell, T. (1981). Seven theories of human society. New York: Oxford University Press.

Canda, E. R. (1988). Spirituality, religious diversity, and social work practice. Social Casework, 69(4), 238-247.

Canda, E. R. (1989). Religious content in social work education: A comparative approach. Journal of Social Work Education, 25(1), 36-45.

Canda, E. R. (1991). East/West philosophical synthesis in transpersonal theory. Journal of Sociology and Social Welfare, 18(4), 137-152.
Canda, E. R. (1996). Does religion and spirituality have a significant place in the core HBSE curriculum? Yes. In M. Bloom \& W. Klein (Eds.), Controversial issues in buman behavior in the social environment (pp. 172-177; 183-184). Needham Heights, MA: Allyn and Bacon.

Canda, E. R., \& Weisman, D. (1997). Does religion and spirituality have a significant place in the core HBSE curriculum? In M. Bloom, \& W. Klein (Eds.), Controversial issues in human behavior in the social environment (pp. 172-184). Boston: Allyn and Bacon.

Chatterjee, P. (1985). Origins of social welfare policy and models of help. Social Development Issues, 93, 27-46.

Chatterjee, P. (1990). The transferability of social technology. Lewiston, N.Y.: Mellen Press.

Chatterjee, P., \& Bailey, D. (1993). Ideology and social structure in social service settings. In P. Chatterjee \& A. J. Abramovitz (Eds.), Structure of nonprofit management. Lanham, MD: University Press of America.

Chatterjee, P., \& Hilbert, H. (1986). Conceptual models of helping and their functions. Journal of Applied Social Sciences, 11, 111-135.

Check, C. L., \& Asquith, S. (1985). Social work and social philosophy, a guide for practice. London: Routledge \& Kegan Paul

Cohen, B. P. (1989). Developing sociological knowledge: Theory and method. Chicago: Nelson Hall.

Dubin, R. (1969). Theory building. New York: Free Press.

Ewalt, P. L., \& Mokuau, N. (1995). Self-determination from a pacific perspective. Social Work, 40, 168-175.

Freedberg, S. (1989). Self-determination: Historical perspectives and effects on current practice. Social Work, 34, 33-38.

Findlay, P. C. (1978). Critical theory and social work practice. Catalyst, 3, 55-67.

Franklin, C. (1995). Expanding the vision of the social constructionist debates: Creating relevance for practitioners. Families in Society, $76(7), 395-406$.

Fischer, J. (1981). The social work revolution. Social Work, 26, 199-207.

Fisher, R., \& Karger, H. J. (1997). Social work and community in a private world: Getting out in public. New York: Longman.

Fraser, M., Taylor, M. J., Jackson, R., \& O'Jack, J. (1991). Social work and science: Many ways of knowing? Social Work Research and Abstracts, 27, 5-15.

Gibbs, L., \& Gambrill, E. (1996). Critical thinking for social workers: A workbook. Thousand Oaks, CA: Pine Forge Press.

Gibson, J. W., \& Nurius, P. S. (1992). Procedural knowledge in education for direct practice: Definitions, baselines and recommendations. Journal of Teaching in Social Work, 6, 21-27.

Gilligan, C. (1982). In a different voice: Psychological theory and women's development. Cambridge: Harvard University Press.

Goldstein, H. (1992). If social work hasn't made progress as a science, might it be an art? Families in Society, 73, 48-55.

Gutierrez, L M., \& Ortega R. (1991). Developing methods to empower Latinos: The importance of groups. Social Work With Groups, 14(2), 23-43.

Hartman, A. (1990). Many ways of knowing [Editorial]. Social Work, $35,3-4$.

Hartman, A. (1992). In search of subjugated knowledge [Editorial]. Social Work, 37, 483-84.

Hartman, A. (1993). The professional is political. Social Work, 38, 365-366, 504.

Harrison, D., Hudson, W., \& Thyer, B. (1992). On a critical analysis of empirical clinical practice: A response to Witkin's revised views [Point and Counterpoint]. Social Work, 37, 461-464. 
Haynes, K. S., \& Holmes, K. A. (1994). Invitation to social work. New York: Longman.

Heineman, M. (1981). The obsolete scientific imperative in social work research. Social Service Review, 55, 371-97.

Herr, K. (1995). Action research as empowering practice. Journal of Progressive Human Services, 6, 45-58.

Howard, A., \& Scott, R. A. (1981). The study of minority groups in complex societies. In R. H. Munroe, R. L. Munroe, \& B. B. Whiting (Eds.), Handbook of cross-cultural development (pp. 113149). New York: Garland Press.

Hudson, W. (1982). Scientific imperatives in social work research and practice. Social Service Review, 56, 246-58.

Imre, R. (1984). The nature of knowledge in social work. Social Work, 29, 41-45.

Kilty, K. M., and Meenaghan, T.M. (1995). Social work and the convergence of politics and science. Social Work, 40, 445-453.

Kirk, S. A. (Ed.) (1996). Special Issue of Social Work Research on the Scientific-Practitioner, 20.

Klein, W. C., and Bloom, M. (1995). Practice wisdom. Social Work, 40, 799-807.

Kondrat, M. E. (1995). Concept, act and interest in professional practice: Implications of an empowerment perspective. Social Service Review, 69, 405-28.

Lee, J. (1994). The empowerment approach to social work practice. New York: Columbia University Press.

Lindsey, D., \& Kirk, S. A. (1992). The continuing crisis in social work research: Conundrum or solvable problem: An essay review. Journal of Social Work Education 28, 370-82.

Minahan, A., \& Pincus, A. (1977). Conceptual framework for social work practice. Social Work, 22, 347-352.

National Association of Social Workers (1996). The National Association of Social Workers Code of Ethics. Insert to NASW News, 41 (10), 4 pages, unnumbered.

Parr, L. E., with B. Husby \& R. Brown (1996). Repressed memory claims in the crime victims compensation program. Unpublished manuscript. Department of Labor and Industries, Crime Victims Compensation Program, Washington.

Pendergrast, M. (1996). Victims of memory (2nd ed.). Hinesberg, VT: Upper Access Books.

Perlman, H. H. (1965). Self-determination: Reality or illusion? Social Service Review, 39, 410-421.

Rapp, C., \& Wintersteen, R. (1989). The strengths model of case management: Results for twelve demonstrations. Journal of Psychosocial Rehabilitation, 13, 23-32.

Reid, W. J. (1994). The empirical practice movement. Social Service Review, 68, 165-184.

Rein, M., \& White, S. H. (1981). Knowledge for practice. Social Service Review, 55, 1-41.

Robbins, S. P. (1984). Anglo concepts and Indian reality: A study of juvenile delinquency. Social Casework, 65(4).

Robbins, S. P. (1995a). Cults. Encyclopedia of Social Work, 19th Edition, Washington DC: NASW Press, 667-677.

Robbins, S. P. (1995b). Wading through the muddy waters of recovered memories. Families in Society, 76 (8), 478-489.

Robbins, S. P. (1997). Cults (update). Encyclopedia of Social Work, 19th Edition on CD ROM. Washington DC: National Association of Social Workers Press.
Robbins, S. P., Chatterjee, P. and Canda, E. R. (1998) Contemporary buman behavior theory: A critical perspective for social work. Boston: Allyn \& Bacon.

Rodwell, M. K. (1987). Naturalistic inquiry: An alternative model for social work assessment. Social Service Review, 61, 231-46.

Rosenthal, B. S. (1992). Does the social work profession value research based knowledge as a basis for social policy? Arete, 17, 38-46.

Rothman, J., Smith, W., Nakashima, J., Paterson, M. A., \& Mustin, J. (1996). Client self-determination and professional intervention: Striking a balance. Social Work, 41, 396-406.

Saleebey, D. (Ed.). (1992). The strengths perspective in social work practice. New York: Longman.

Saleebey, D. (1996). The strengths perspective in social work practice: Extensions and cautions. Social Work, 41, 296-305.

Sheldon, B. (1978). Theory and practice in social work: A re-examination of a tenuous relationship. British Journal of Social Work, 8, $1-22$.

Simon, B. (1994). The empowerment tradition in American social work: A bistory. New York: Columbia University Press.

Staller, K. M., \& Kirk, S. A. (1998). Knowledge utilization in social work and legal practice. Journal of Sociology and Social Welfare, 25, 91-113.

Stocks, J. T. (1998). Recovered memory therapy: A dubious practice technique. Social Work, 43, 423-436.

Trattner, W. I. (1986). From poor law to welfare state: A history of social welfare in America (3rd ed.), New York: Free Press.

Tucker, D. J. (1996). Eclecticism is not a free good: Barriers to knowledge development in social work. Social Service Review, 70, 400434.

Valenstein, E. S. (1998). Blaming the brain: The truth about drugs and mental bealth. New York: Free Press.

Von Staden, H. (1996). In a pure and holy way: Personal and professional conduct in the Hippocratic Oath. Journal of the History of Medicine and Allied Sciences, 51 406-408.

Weick, A. (1987). Reconceptualizing the philosophical perspective of social work. Social Service Review, 61, 218-230.

Weick, A., \& Pope L. (1988). Knowing what's best: A new look at selfdetermination. Social Casework, 69, 10-16.

Weick, A., Rapp, C., Sullivan, P., \& Kisthardt, W. (1989). A strengths perspective for social work practice. Social Work, 34, 350-354.

Weick, A., \& Saleebey, D. (1995). Supporting family strengths: Orienting policy and practice toward the 21st century. Families in Society, 76, 141-149.

Witkin, S. (1991). Empirical clinical practice: A critical analysis. Social Work, 36, 158-163.

Witkin, S. (1992). Empirical clinical practice or Witkin's revised views: Which is the issue? Social Work, 37, 465-68.

Witkin, S. L., \& Gottschalk, S. (1988). Alternative criteria for theory evaluation. Social Service Review, 62(2), 211-224.

Susan P. Robbins is associate professor, and associate dean for Academic Affairs, University of Houston, Graduate School of Social Work, Houston, TX 77204. Pranab Chatterjee is professor, Case Western Reserve University, Mandel School of Applied Social Sciences. Edward R. Canda is associate professor, University of Kansas, School of Social Welfare. 